\title{
PERSPECTIVE
}

\section{Meiotic recombination and male infertility: from basic science to clinical reality?}

\author{
Michael C Hann*, Patricio E Lau* and Helen G Tempest
}

Infertility is a common problem that affects approximately $15 \%$ of the population. Although many advances have been made in the treatment of infertility, the molecular and genetic causes of male infertility remain largely elusive. This review will present a summary of our current knowledge on the genetic origin of male infertility and the key events of male meiosis. It focuses on chromosome synapsis and meiotic recombination and the problems that arise when errors in these processes occur, specifically meiotic arrest and chromosome aneuploidy, the leading cause of pregnancy loss in humans. In addition, meiosis-specific candidate genes will be discussed, including a discussion on why we have been largely unsuccessful at identifying disease-causing mutations in infertile men. Finally clinical applications of sperm aneuploidy screening will be touched upon along with future prospective clinical tests to better characterize male infertility in a move towards personalized medicine.

Asian Journal of Andrology (2011) 13, 212-218; doi:10.1038/aja.2011.1; published online 7 February 2011

Keywords: fluorescent in situ hybridization; immunofluorescence; male infertility; meiotic recombination; semen parameters; synaptonemal complex

\section{INTRODUCTION}

Infertility is a relatively common problem in humans, estimated to affect around one in six couples worldwide wishing to start a family ${ }^{1}$ which is similar to the incidence of diseases associated with lifestyle, such as diabetes or hypertension. ${ }^{2}$ Fertility is an extraordinarily complex process that involves gamete formation, transport, fertilization and implantation which is dependent on numerous pathways and interactions. Clearly, the large number of pathways and hundreds of genes involved in this process provides an equally large number of opportunities for development to go awry, leading to infertility. Given this, infertility has a diverse range of phenotypes, the etiology of which appears to affect both males and females equally, with a relatively equal distribution among male factors, ovarian dysfunction and tubal factors. ${ }^{2}$ However, the large majority of cases continue to be diagnosed as idiopathic, reflecting a poor understanding of the molecular and genetic defects underlying infertility phenotypes. ${ }^{3}$

\section{CURRENT MALE FERTILITY TESTING}

Typically, fertility tests in men involve semen parameter analysis utilizing strict guidelines from the World Health Organization. ${ }^{4}$ Male infertility is defined by defects and reductions in sperm count (oligozoospermia), motility (asthenozoospermia) and morphology (teratozoospermia) as defined by the World Health Organization. Additionally, the semen sample is examined for the presence of other cells, indicators of patency and function of the genital tract amongst others. ${ }^{4}$ Despite our ability to identify semen parameter defects that contribute to male factor infertility, the genetic and molecular basis underlying these defects is rarely identified.

\section{KNOWN GENETIC FACTORS ASSOCIATED WITH MALE FACTOR INFERTILITY}

Analysis of chromosome aberrations (karyotyping) is frequently offered as part of the fertility workup. Karyotype analysis is recommended and routinely performed for couples who experience repeated spontaneous abortions and men with oligozoospermia, even in the absence of other clinical presentations. Karyotype abnormalities, be they structural or numerical in nature, are observed in $0.4 \%$ of liveborns, but infertility is associated with increased levels of chromosome aberrations ${ }^{5}$ affecting $2 \%$ of males presenting with fertility problems; $6 \%$ of oligozoospermic and $14 \%$ of non-obstructive azoospermic (NOA) males. ${ }^{6}$ In fact, the most common genetically identifiable cause of male factor infertility is Klinefelter syndrome, which is a condition that arises as the result of an additional sex chromosome $(47, \mathrm{XXY})$ in the somatic karyotype.

The second most common genetic cause of male infertility is the presence of microdeletions on the $\mathrm{Y}$ chromosome, which accounts for a large proportion of azoospermia. ${ }^{7}$ Three regions on the q-arm of the $\mathrm{Y}$ chromosome have been referred to as 'azoospermia factors' (AZFa, AZFb and AZFc proximal to distal respectively), which have been defined as spermatogenesis loci. ${ }^{8}$ In addition, the regions involved in the deletion can offer valuable prognostic information (reviewed by Krausz et al. ${ }^{9-11}$ ). In brief, microdeletion of the entire $\mathrm{AZFa}$ or $\mathrm{AZFb}$ regions of the $\mathrm{Y}$ chromosome portends an exceptionally poor prognosis for sperm retrieval, whereas the majority of men with AZFc deletions have sperm available either within their semen or retrievable from their testes for use in assisted reproductive technologies. $^{12}$

\footnotetext{
Department of Human and Molecular Genetics, Herbert Wertheim College of Medicine, Florida International University, Miami, FL 33199, USA

* These authors contributed equally to this work.

Correspondence: Dr HG Tempest (htempest@fiu.edu)

Received: 2 December 2010; Accepted: 6 January 2011; Published online: 7 February 2011
} 
Another genetic cause of male infertility involves a single gene mutation in the cystic fibrosis transmembrane conductance regulator gene. In approximately $80 \%$ of cases, fibrosis transmembrane conductance regulator mutations on both alleles lead to a condition known as congenital bilateral absence of the vas deferens. ${ }^{13}$ The absence of the vas deferens in this condition is a phenotype that prevents the normal transport of sperm and thus leads to male infertility. ${ }^{13}$

To date it has been estimated that genetic factors including chromosome aberrations and single gene defects account for approximately $10 \%-15 \%$ of severe male factor infertility. ${ }^{14}$ It is inevitable that as our understanding of genetic and molecular mechanisms of gamete formation, transport, fertilization and implantation improves that most, if not all male infertility will have some identifiable genetic component. One such example includes a study that reports up to $6 \%$ of male patients presenting to infertility clinics with a normal somatic karyotype have been found to have meiotic alterations in their spermatogenic cells. ${ }^{15}$

\section{OVERVIEW OF MAMMALIAN MEIOSIS}

Meiosis is a specialized form of cell division that only takes place in the gametes and is essential for the completion of spermatogenesis. Meiosis is a critical step in gamete formation that gives rise to four gametes with a haploid chromosome complement from a single diploid precursor cell; in essence chromosomes undergo one replication event followed by two reduction divisions. Errors in meiotic recombination can give rise to gamete aneuploidy (presence of extra or missing chromosomes), which is the leading cause of pregnancy loss and developmental disabilities in humans. This review will focus on our current understanding of errors in male meiotic recombination, in particular how these contribute to male factor infertility, their clinical relevance and the translation from basic science to clinical application will be discussed when applicable.

The process of meiosis is essential for mammalian gamete formation and has been reviewed extensively elsewhere. ${ }^{16-19}$ Nevertheless there are several key processes that take place during meiosis that are critical for gamete formation and correct chromosome segregation, these will be reviewed in detail along with their role in male infertility. The vast majority of meiotic genes have been identified in yeast and murine models which have provided strong evidence of the catastrophic effects on fertility if meiotic genes are perturbed. Such studies have undoubtedly provided insight into male infertility and published studies investigating meiotic genes in humans will be discussed.

\section{MEIOTIC PROPHASE I}

Perhaps the two major events during meiosis from a genetic standpoint take place during prophase I and include: (i) homologous (maternal and paternal) chromosome pairs locate each other and become physically connected (synapsis); and (ii) genetic exchange (recombination) takes place ensuring genetic diversity of the species. Both chromosome synapsis and recombination appear to play a vital role in correct chromosome segregation by ensuring that homologous chromosomes remain tethered together until the appropriate time.

Meiosis in males is initiated at puberty during prophase of meiosis I when homologous chromosomes pair and synapse. Prophase I is divided into four stages based on the morphology of the XY bivalent and the synaptic progression of the autosomal bivalents. ${ }^{20}$ These stages are: leptotene, zygotene, pachytene and diplotene. Programmed double strand breaks (DSBs) are formed and marked for repair in the leptotene stage. The zygotene stage includes homology searches between homologous chromosomes and the initiation of synapsis.
The completion of synapsis of homologous chromosomes and the repair of DSBs, using homologous chromosomes as templates, occurs from mid-zygotene through to the pachytene stages. At the end of the diplotene stage, desynapsis of homologous chromosomes begins except for foci of reciprocal exchange, which continues forward in meiosis as chiasmata that are essential for correct chromosome segregation. ${ }^{18}$

The first meiotic division is reductional and separates homologous chromosomes, producing two secondary spermatocytes. The second meiotic division occurs immediately after the first division resulting in an equatorial division and the separation of sister chromatids. The net result of this process is the production of four haploid spermatids.

\section{MEIOTIC GENE MURINE MODELS}

Gene-modified mouse models have demonstrated that genetic defects in meiotic genes can cause catastrophic reproduction failure, suggesting the possibility that reduced fertility in a proportion of males is likely caused by defects in meiotic regulatory genes. ${ }^{2,18}$ In fact, there are over 400 mouse models where the occurrence of aberrant reproductive phenotypes results in male infertility which is frequently unforeseen, but quite common. ${ }^{17}$ Numerous genes have been identified in mutant mouse models and can be characterized by specific abnormalities involving meiotic progression, chromosome pairing and recombination.

Gene knockout models have led to the identification of key proteins involved in chromosome synapsis and recombination enabling immunofluorescence techniques to be developed to study meiosis in males (Figure 1). ${ }^{21,22}$ Such meiotic studies have undoubtedly furthered our understanding of meiosis. However, one major drawback of such studies is the requirement for testicular biopsies. Thus, for the most part these studies are restricted to NOA and obstructive azoospermic (OA) individuals, with vasectomy reversal and testicular cancer patients forming control groups.

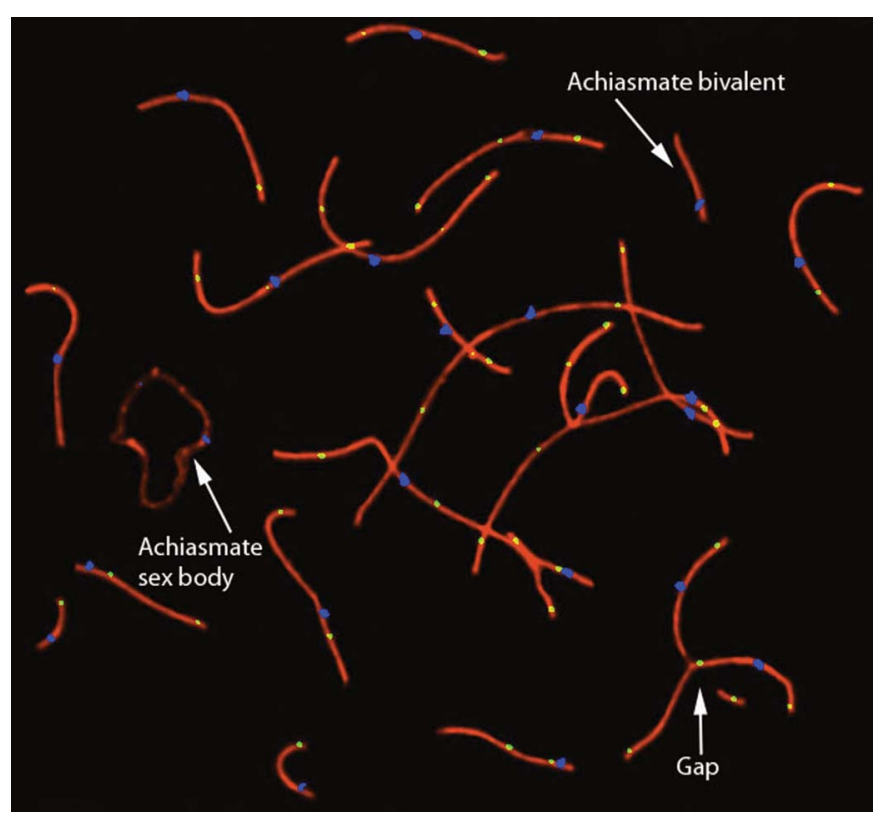

Figure 1 Example of a human pachytene spermatocyte. SCs are shown in red, centromeres in blue and recombination foci in yellow. Indicated are: two achiasmate bivalents (including the sex body and an acrocentric bivalent) and an example of a discontinuity in the SC (gap). SC, synaptonemal complex. 


\section{THE ROLE OF THE SYNAPTONEMAL COMPLEX IN} CHROMOSOME SYNAPSIS AND MEIOTIC ARREST

Chromosome synapsis begins with the formation of the synaptonemal complex (SC). The SC is composed of transversely and axially arranged proteins (SCP1 and SCP3, respectively) that join up homologous chromosomes during prophase I in meiosis. ${ }^{23}$ Timing and progression of SC formation is strictly organized and maintained, ${ }^{24,25}$ but occasionally, errors in SC formation occur. Chromosome synapsis errors include the formation of splits (unpaired regions) and gaps (discontinuities) (Figure 1). ${ }^{25,26}$ Aberrations in chromosome synapsis frequently occur in the heterochromatic regions of chromosomes 1 and 9 and have been reported in all investigated groups (controls, NOA and OA patients). ${ }^{25,27}$ However, a significant increase in the percentage of cells containing unsynapsed regions have been observed in NOA and OA men compared to controls (20, 10 and 8\%, respectively) ${ }^{28}$ This clearly has important clinical ramifications as asynapsis in pachytene may arise from a primary meiotic defect that could result in an increased probability of atresia. ${ }^{29-32}$ High frequencies of asynapsed regions in pachytene, likely prevent the normal progression of meiotic prophase substages. Asynapsed regions may trigger a checkpoint that leads to partial or complete spermatogenic arrest as a result of severe meiotic defects and hence results in the NOA phenotype. ${ }^{33}$

\section{MEIOTIC RECOMBINATION}

Meiotic recombination is mechanistically responsible for providing the physical connections that ensure proper alignment and segregation of chromosomes during cell division through the formation of chiasmata. ${ }^{34}$ The process of meiotic recombination is essential for fertility and integrity of the genome. During prophase I, DSBs are induced and parental chromosomes are paired based on homologous sequences. An intact homologous chromosome template is then used to repair the DSBs. Homologous recombination also occurs in somatic cells; however, in these cells, a sister chromatid is used as a template for repair in lieu of an intact homologous chromosome. This is a key distinction, and results in the reciprocal exchange of genetic sequences between homologous chromosomes and a complement of alleles that are not associated with each other on either of the parental chromosomes. ${ }^{18}$ The result of this meiotic process is the reciprocal exchange of genetic information, creating genetic diversity.

As with SC formation, the process of meiotic recombination is strictly controlled, both in number and localization of recombination events. Eighty to ninety percent of cells are found to be in the pachytene stage of meiosis in control males as it is the longest phase. ${ }^{26,33,35,36}$ Comparatively, a large percentage of NOA males have been identified as completely lacking meiotic cells $(45-53 \%),{ }^{26,33,36,37}$ or severely reduced frequencies (approximately 10\% versus $80-90 \%$ ) due to a partial or complete block at the zygotene stage. ${ }^{35}$ The average number of recombinatorial events per cell in control males has been shown to be approximately 50 through cytogenetic studies and immunofluorescence data. ${ }^{36,38-42}$ There is a significant degree of variability between controls (13-25\%) and between cells from the same individual (range: $42.5-55.3$ recombination foci per cell). ${ }^{39-42}$ The majority of published studies provide evidence of a significant reduction in recombination events per cell in NOA individuals compared to controls (40-42 versus 46-49)..$^{33,35,36}$ Two studies have reported no such difference in overall recombination between NOA and controls. ${ }^{26,43}$

\section{ABSENCE OF MEIOTIC RECOMBINATION}

Achiasmate bivalents (bivalents lacking a recombination event) have been reported in all investigated patient groups (Figure 1). The frequency of achiasmate bivalents in NOA males has been reported to occur in up to $29 \%$ of investigated pachytene spreads, significantly higher than the $0.1-5 \%$ reported in controls. Studies that have karyotyped SCs by fluorescent in situ hybridization (FISH) have revealed that chromosomes 21, 22, $\mathrm{X}$ and $\mathrm{Y}$ are the most frequently involved. Given that the bivalents in question almost exclusively only possess one recombinatorial event, rather than two or more as found for all other bivalents this finding is perhaps, not unexpected. ${ }^{42,44,45}$ When considering the sex chromosomes alone (distinguishable without FISH), there are mixed reports; including several NOA individuals with a complete absence of recombination in the sex body ${ }^{26,46}$ and one report stating no significant difference between NOA and control groups. ${ }^{26}$ It should be noted that this study does report a significant increase in achiasmate sex bodies for individual NOA men compared to controls. ${ }^{26}$ Achiasmate bivalents are clinically relevant as these bivalents theoretically are unable to orientate themselves on the metaphase plate in order to ensure correct chromosome segregation in the resultant daughter cells. ${ }^{33}$ Therefore, reduced or absent meiotic recombination may lead to increased sperm aneuploidy frequencies, or even spermatogenic arrest, resulting in infertility. ${ }^{36,47,48}$

\section{MEIOTIC GENES INVESTIGATED IN INFERTILE MEN}

Over 75 genes in male infertility mouse models have been identified that when disturbed, can perturb chromosome pairing and synapsis, recombination, aneuploidy, DNA replication and repair in spermatocytes. ${ }^{17}$ However, to date, only a handful of studies investigating meiotic gene mutations in infertile human men have been conducted. For most part, disease-causing mutations involved in male meiosis have remained largely elusive with the exception of SPO11 and SYCP3 mutations. ${ }^{3,49}$ Several other studies have investigated genes including SYCP3, SPO11, FKBP6, BOULE, H2AX and REC8, but have failed to identify any disease-causing mutations. ${ }^{3,50-57}$

The initiation of meiotic recombination is regulated in a large part by the protein SPO11. The SPO11 protein is a type II topoisomerase required for DSB formation in the leptotene stage. ${ }^{58}$ Errors in meiotic recombination have been reported in SPO $11^{-1-}$ mice models, which are infertile and have smaller gonads than wild-type or heterozygote mice. ${ }^{18}$ Additionally, yeast SPO11 mutants show a range of phenotypes from partial loss of function, to complete loss of DSB formation. ${ }^{59}$ Both spermatocytes and oocytes from SPO11 ${ }^{-1-}$ mice have been demonstrated to undergo apoptosis during pachytene and diplotene, respectively. ${ }^{18}$ Although mutations in SPO11 and its regulatory sequences do not appear to be a common contributor to human male infertility, when they are present, formation of DSBs appears to be greatly affected. ${ }^{18}$ Two NOA patients $(n=144)$ with SPO11 missense mutations in exons 1 and 9 of the SPO11 gene and 16 single nucleotide polymorphisms in intron regions have been identified. ${ }^{18}$ However, Mori et al. $^{52}$ did not identify any disease causing mutations in SPO11 in 53 NOA patients.

The SYCP3 (or SCP3) gene has been shown to encode a DNAbinding protein that is involved in mediating synapsis between homologous chromosomes during meiosis and forms a key structural component of the SC. SYCP3 has clearly been shown to result in meiotic arrest when absent in mouse knockout models, ${ }^{60-62}$ as a result of massive apoptotic cell death during meiotic prophase I due to SC formation failure. ${ }^{62}$ Two azoospermic individuals $(n=19)$ with maturation arrest have been shown to have a 1-bp deletion (643delA) resulting in a premature stop codon and truncation of the C-terminal, coiled coil-forming region of the SYCP3 protein. ${ }^{3}$ The resultant mutant protein demonstrated significantly reduced 
interaction with the wild-type protein in vitro and interfered with SYCP3 fiber formation in cultured cells. ${ }^{3}$ However, two other published studies have not identified any disease-causing mutations in SYCP3 ( $n=58$ and $n=22) .{ }^{50,55}$ It is of note that the patient population recruited to these studies contained heterogeneous infertility phenotypes including azoospermia, severe oligozoospermia, Y-chromosome microdeletions, and complete and incomplete maturation arrest.

\section{GENOME EXPRESSION PROFILING TO IDENTIFY MEIOTIC GENES}

Perhaps the easiest manner in which we can characterize meiotic genes is through whole-genome expression profiling using oligonucleotide microarrays, but such gene sets often include non-meiotic genes. A recent elegantly designed study has developed a novel strategy to investigate meiotic-specific genes in mice and characterized a subset of the identified gene products using reverse transcription-PCR of RNA. $^{2}$ This study utilized meiotic cells that were fractionated and enriched by gravity sedimentation from mouse developing testis, thus allowing the expression profiles of different enriched meiotic cells to be investigated. This study has identified a total of 726 meiotic-specific candidate genes that were upregulated during the leptotene/zygotene stage. Human orthologs of these genes are potential candidates for meiotic arrest and potentially chromosome aneuploidy. ${ }^{2}$

\section{THE RELATIONSHIP BETWEEN CHROMOSOME ANEUPLOIDY AND MALE INFERTILITY}

The majority of men presenting with infertility are karyotypically normal but have reduced semen parameters as defined by the World Health Organization. ${ }^{4}$ Perhaps one of the most striking observations is that infertile men have significantly increased sperm aneuploidy levels (investigated by FISH analysis) compared to their fertile counterparts. Increased sperm aneuploidy levels have been reported in infertile men for all abnormal semen profiles (oligozoospermia, asthenozoospermia, teratozoospermia and azoospermia). ${ }^{63,64}$ This finding has obvious clinical ramifications given the fact that aneuploidy, albeit predominantly maternal in origin (except for the sex chromosomes), is the leading cause of pregnancy loss and developmental disabilities in humans. ${ }^{47}$ Increased aneuploidy frequencies in infertile men have been reported for all investigated chromosomes. It should be noted that the nuclear position the chromosome probe occupies and the probe signal size has been suggested to influence the perceived levels of aneuploidy. ${ }^{65}$ However, it is clear that certain chromosomes are more prone to non-disjunction (chromosomes 21, 22, X and Y); with a two- to threefold increase in aneuploidy levels for these chromosomes compared to other chromosomes. Indirect evidence of the requirement for meiotic recombination for correct chromosome segregation has been provided by the observation that achiasmate bivalents predominantly involve chromosomes $21,22, \mathrm{X}$ and $\mathrm{Y}$; mirroring the observation that these are most commonly observed chromosome aneuploidies in sperm. Further evidence that achiasmate bivalents can give rise to sperm aneuploidy has been demonstrated by the observation that the majority of 47,XXY conceptuses of paternal origin have arisen as a result of failure of recombination between the paternal sex chromosomes. ${ }^{66}$ Additionally, there is recent evidence of a correlation between increased sperm aneuploidy and achiasmate bivalents in NOA patients. ${ }^{26,67}$

The majority of aneuploidy studies in sperm from infertile men report around a threefold increase in sperm aneuploidy levels compared to controls, with levels of up to 10-fold being reported; predominantly for severe infertility (severe oligoasthenoteratozoospermia and azoospermia). ${ }^{68,69}$ There are a few case reports of extraordinarily high levels of aneuploid and polyploid sperm (50-100\%) in individuals with a high proportion of macrocephalic, multinucleated and multiflagellate sperm..$^{70-73}$ It perhaps counterintuitive but there is little or no evidence to suggest that there is a preferential selection of chromosomally normal sperm for fertilization. In fact, the threefold increase in aneuploidy observed in sperm from infertile men, is mirrored by a threefold increase in de novo chromosome abnormalities observed in conceptuses after intracytoplamic sperm injection compared to the general population. ${ }^{74}$

\section{SUMMARY}

To date, only a relatively small subset of infertile human men have been studied and reported in the literature. Despite this, we can clearly identify meiotic abnormalities in chromosome pairing, meiotic progression and meiotic recombination in humans associated with male infertility by immunofluorescence and FISH. Additionally, there is emerging evidence suggesting a correlation between errors in synapsis and recombination that lead to spermatogenic arrest and increasing levels of aneuploidy in the gametes which has obvious clinical ramifications. Intuitively impairment of chromosome segregation will have a major impact on the process of meiosis and therefore spermatogenesis. Two lines of evidence strongly suggest that the mechanism of action may involve aberrant chromosome synapsis and meiotic recombination. Firstly, studies investigating meiosis in pachytene spermatocytes suggest that azoospermia is, at least in part, related to an inadequate chromosome pairing and/or synapsis. ${ }^{35,67}$ Secondly, reduced or absent recombination has been associated with paternally derived XXY trisomy. ${ }^{75}$ Meiotic recombination mediates a critical meiotic checkpoint, which ensures that all chromosomes are correctly paired. In the absence of correct chromosome pairing, these cells are subsequently eliminated leading to azoospermia or oligozoospermia. However, the system is not perfect and some cells escape the meiotic checkpoint and hence have a higher risk of aneuploidy as a result of aberrant chromosome synapsis and/or recombination. What is hitherto poorly understood and remains the subject of future research is the precise mechanism(s) by which aberrant chromosome pairing and reduced recombination occurs in infertile men.

\section{ISSUES ASSOCIATED WITH IDENTIFYING MUTATIONS IN HUMAN MEIOTIC GENES}

The identification of disease-causing mutations in human meiotic genes remains a potentially rich source of genetic aberrations that may provide the basis of a variety of infertility phenotypes, particularly for those involving spermatogenic arrest and increased sperm aneuploidy. However, to date, the identification of mutations in such meiotic genes remains largely elusive and somewhat disappointing with reported mutations in only two genes SPO11 and SYCP3. The reasons for this are numerous; to date, only a handful of meiotic genes in humans have been analyzed with potentially hundreds of genes remaining to be characterized. Thus, although a large number of genes have been identified in mice models, we have yet to characterize many of the genes in humans that regulate the initiation, progression and completion of meiosis. Mutations in human meiotic genes may be relatively rare and the patient sample size in most studies is extraordinarily small, and thus may explain the lack of identified mutations. The issue is further confounded when the large heterogeneous etiology of infertility is considered. Mutations will probably be restricted to a subset of patients, and problems arise as patients may be included in a heterogeneous study group due to the unspecific 
nature of the designation of their infertility. There is clearly a requirement for an appropriate collection of well-characterized patients with clearly defined meiotic defects to be enrolled in each study, likely only achievable through large multicenter studies, which is associated with its own problems. Specifically, the categorization of infertile men into azoospermic or oligozoospermia may not be specific enough to identify a patient group that has a truly homozygous etiology for infertility. For example, it is likely that a mutation in a gene that causes a complete block at leptotene will be different from one that results in a block at zygotene or one in which some cells are capable of progressing to pachytene for example. The issue is further confounded by the fact that prophase I is a complicated biological process mediated by potentially hundreds of genes and perhaps by complex gene interactions. ${ }^{2,76,77}$ Researchers are also facing a major challenge applying yeast data to humans, given that meiotic genes tend not to be orthologous. Additionally, mutations in humans are most likely to be heterozygous mutations which will probably produce considerably milder phenotypes than those observed in homozygous animal models, in which mutations often encompass large parts of the gene or complete knockouts. Heterozygous mutations will most likely not result in the catastrophic reproductive phenotypes observed in mouse models. Nevertheless, such mutations may produce germ cells that have higher aneuploidy frequencies, but that are still capable of completing meiosis because of the heterozygous nature of the mutation. Another confounding fact is that by definition male infertility mutations may in some cases arise de novo, which precludes familial linkage analysis. However, one elegantly designed study has evaluated 172 candidate polymorphisms for associations with oligozoospermia and NOA, and has suggested that male factor infertility is likely to be multigenic. ${ }^{78}$ The majority of complex diseases studied to date, have proven to be multigenic; ${ }^{79}$ this current male infertility genome-wide association study supports this theory. ${ }^{78}$ This finding explains why no single nucleotide polymorphism has been identified that accounts for any particular male infertility phenotype. The authors go on to suggest that infertility phenotypes may arise as a result of a large number of rare variants with a small effect that in combination are the cause of spermatogenic failure, ${ }^{78}$ thus requiring much larger multicenter genome-wide studies perhaps involving thousands of individuals with well-characterized male infertility phenotypes to be undertaken; which is by no means a simple task. Additionally, structural variations within the genome such as copy number variants may also play a role in male infertility and should be investigated in these patient cohorts. ${ }^{78}$

\section{CLINICAL APPLICATION OF SPERM ANEUPLOIDY SCREENING}

Sperm aneuploidy studies have proven to be a valuable research tool that has enhanced our understanding of the paternal contribution of aneuploidy. Research thus far has shown that infertile men (in particular severe oligoasthenoteratozoospermia and azoospermic individuals) have significantly increased errors in chromosome synapsis and meiotic recombination compared to their fertile counterparts, leading to increased chromosome non-disjunction. Clinical testing of aneuploidy frequencies in sperm is relatively simple to achieve and has been initiated in some clinics. However, sperm aneuploidy screening does suffer from some drawbacks that are not insurmountable but have precluded widespread clinical application. These have been reviewed in detail elsewhere, but in brief include: (i) requirement to score 5-10 000 sperm; (ii) frequently only 2-5 chromosomes are tested; (iii) the individual sperm to be used for fertility treatment cannot be screened; therefore, it can only provide an assessment of risk; (iv) there is a need to identify individuals who would benefit from screening; and (v) the clinical significance of increased sperm aneuploidy still remains unclear. ${ }^{21}$ Nevertheless, only through continued research into meiotic recombination errors and prospective sperm aneuploidy studies will it be possible to gain a better understanding of the clinical significance of increased sperm aneuploidy. It is clear from the scientific literature that several patient groups could benefit from clinical aneuploidy screening prior to fertility treatment given the significantly higher sperm aneuploidy frequencies observed. These include: (i) Klinefelter syndrome patients; (ii) patients with cytogenetically visible structural chromosome aberrations; (iii) NOA patients (should enough sperm be available for treatment and screening); (iv) oligoasthenoteratozoospermic patients; (v) patients with a history of unexplained recurrent pregnancy loss or repeated in vitro fertilization or intracytoplamic sperm injection failure; and (vi) patients with very high levels macrocephalic, multinucleated and multiflagellate sperm. $^{21,80-83}$ Performing routine sperm aneuploidy screening in these patients will enable a more individualized risk assessment of aneuploid offspring. For example, the genetic counseling of a patient with low levels of sperm aneuploidy (comparable to fertile controls) will be very different to that of an individual with $40 \%$ aneuploid sperm. This will ultimately allow couples to make more informed choices about their reproductive future based on their individualized risks. $^{21}$

\section{EMERGING RESEARCH IN THE FIELD OF MALE INFERTILITY}

Perhaps some of the most exciting research in the field is from emerging studies that suggest that the process of spermatogenesis and fertilization is potentially mediated through a variety of other mechanisms that might be associated with infertility phenotypes, including: epigenetic modifications, ${ }^{84,85}$ ubiquitination, ${ }^{86,87}$ genome organization perturbations, ${ }^{88}$ spermatozoal RNAs, ${ }^{89}$ proteomics, ${ }^{90}$ environmental contaminants and pharmacological agents that may contribute to sperm DNA damage ${ }^{91}$ among others.

\section{FUTURE CLINICAL PERSPECTIVES FOR MALE FACTOR INFERTILITY}

The research field of reproductive genetics in male infertility is striving towards being able to offer personalized medicine to identify the genetic and molecular basis of male infertility phenotypes. One such example of a personalized approach was previously published demonstrating in a small cohort of men, a significant reduction in sperm aneuploidy levels coincident with traditional Chinese herbal medicine treatment for male infertility. ${ }^{82,92}$ The ultimate goal has to be the ability to offer valuable clinical prognostic options with appropriate treatment options as a result of the genetic basis of the infertility phenotype. This clearly remains a question for basic science at present and for the immediate future. Nevertheless, such goals have already been achieved through the identification of Y-chromosome microdeletions in azoospermic men, for which clearly defined genotypephenotype correlations exist depending on the AZF region the microdeletion encompasses.

\section{CONCLUSION}

Current semen analysis is a very limited test at best. Research suggests that as genomic technologies advance, we are likely to see the advent of fertility specific microarray chips that will contain genes known to be involved in gamete formation, transport and fertilization ${ }^{86}$ along with a battery of other tests including epigenetic and proteomic tests to better characterize and identify the genetic basis of male infertility 
phenotypes. Unlike the current situation, this will ultimately enable patients attending fertility clinics to be offered a comprehensive diagnosis (rather than idiopathic infertility), along with valuable prognostic information allowing individualized medicine and treatment options.

\section{COMPETING FINANCIAL INTERESTS}

The authors declare no competing financial interests.

1 de Kretser DM. Male infertility. Lancet 1997; 349: 787-90.

2 Kogo H, Kowa-Sugiyama H, Yamada K, Bolor H, Tsutsumi M et al. Screening of genes involved in chromosome segregation during meiosis I: toward the identification of genes responsible for infertility in humans. J Hum Genet 2010; 55: 293-9.

3 Miyamoto T, Hasuike S, Yogev L, Maduro MR, Ishikawa M et al. Azoospermia in patients heterozygous for a mutation in SYCP3. Lancet 2003; 362: 1714-9.

4 WHO. WHO Laboratory Manual for the Examination of Human Semen and SpermCervical Mucus Interaction. 3rd ed. New York: Cambridge University Press; 1993.

5 McLachlan RI, O'Bryan MK. Clinical review\#: state of the art for genetic testing of infertile men. J Clin Endocrinol Metab 2010; 95: 1013-24.

6 Shi Q, Martin RH. Aneuploidy in human sperm: a review of the frequency and distribution of aneuploidy, effects of donor age and lifestyle factors. Cytogenet Cell Genet 2000; 90: 219-26.

7 Stahl PJ, Masson P, Mielnik A, Marean MB, Schlegel PN et al. A decade of experience emphasizes that testing for $Y$ microdeletions is essential in American men with azoospermia and severe oligozoospermia. Fertil Steril 2010; 94: 1753-6.

8 Vogt PH, Edelmann A, Kirsch S, Henegariu O, Hirschmann P et al. Human Y chromosome azoospermia factors (AZF) mapped to different subregions in Yq11. Hum Mol Genet 1996; 5: 933-43.

9 Krausz C, Forti G, McElreavey K. The Y chromosome and male fertility and infertility. Int J Androl 2003; 26: 70-5.

10 Vogt PH. Genomic heterogeneity and instability of the AZF locus on the human $Y$ chromosome. Mol Cell Endocrinol 2004; 224: 1-9.

11 Sadeghi-Nejad H, Oates RD. The Y chromosome and male infertility. Curr Opin Urol 2008; 18: 628-32.

12 Hopps CV, Mielnik A, Goldstein M, Palermo GD, Rosenwaks Z et al. Detection of sperm in men with $\mathrm{Y}$ chromosome microdeletions of the AZFa, AZFb and AZFc regions. Hum Reprod 2003; 18: 1660-5.

13 Claustres M. Molecular pathology of the CFTR locus in male infertility. Reprod Biomed Online 2005; 10: 14-41.

14 Ferlin A, Arredi B, Foresta C. Genetic causes of male infertility. Reprod Toxicol 2006; 22: 133-41.

15 Egozcue S, Blanco J, Vendrell JM, Garcia F, Veiga A et al. Human male infertility: chromosome anomalies, meiotic disorders, abnormal spermatozoa and recurrent abortion. Hum Reprod Update 2000; 6: 93-105.

16 Handel MA, Schimenti JC. Genetics of mammalian meiosis: regulation, dynamics and impact on fertility. Nat Rev Genet 2010; 11: 124-36.

17 Matzuk MM, Lamb DJ. The biology of infertility: research advances and clinical challenges. Nat Med 2008; 14: 1197-213.

18 Sanderson ML, Hassold TJ, Carrell DT. Proteins involved in meiotic recombination: a role in male infertility? Syst Biol Reprod Med 2008; 54: 57-74.

19 Cohen PE, Pollack SE, Pollard JW. Genetic analysis of chromosome pairing, recombination, and cell cycle control during first meiotic prophase in mammals. Endocr Rev 2006; 27: 398-426.

20 Solari AJ, Tres LL. The three-dimensional reconstruction of the XY chromosomal pair in human spermatocytes. J Cell Biol 1970; 45: 43-53.

21 Tempest HG. Meiotic recombination errors, the origin of sperm aneuploidy and clinical recommendations. Syst Biol Reprod Med 2011; 57: 93-101.

22 Ko E, Martin RH. Immunofluorescence analysis of human spermatocytes. Methods Mol Biol 2009; 558: 401-18.

23 Topping D, Brown P, Hassold T. The immunocytogenetics of human male meiosis: a progress report. In: Carrell DT, editor. The Genetics of Male Infertility. Totowa, NJ: Humana Press Inc.; 2007. pp115-28.

24 Baker SM, Plug AW, Prolla TA, Bronner CE, Harris AC et al. Involvement of mouse MIh1 in DNA mismatch repair and meiotic crossing over. Nat Genet 1996; 13: 336 42.

25 Sun F, Oliver-Bonet M, Liehr T, Starke H, Ko E et al. Discontinuities and unsynapsed regions in meiotic chromosomes have a trans effect on meiotic recombination of some chromosomes in human males. Cytogenet Genome Res 2007; 119: 27-32.

26 Ferguson KA, Wong EC, Chow V, Nigro M, Ma S. Abnormal meiotic recombination in infertile men and its association with sperm aneuploidy. Hum Mol Genet 2007; 16 : 2870-9.

27 Sun F, Kozak G, Scott S, Trpkov K, Ko E et al. Meiotic defects in a man with nonobstructive azoospermia: case report. Hum Reprod 2004; 19: 1770-3.

28 Martin RH. Meiotic chromosome abnormalities in human spermatogenesis. Reprod Toxicol 2006; 22: 142-7.

29 Egozcue J, Templado C, Vidal F, Navarro J, Morer-Fargas F et al. Meiotic studies in a series of 1100 infertile and sterile males. Hum Genet 1983; 65: 185-8.
30 Hulten M. Meiosis in XYY men. Lancet 1970; 1: 717-8.

31 Guichaoua MR, Perrin J, Metzler-Guillemain C, Saias-Magnan J, Giorgi R et al. Meiotic anomalies in infertile men with severe spermatogenic defects. Hum Reprod 2005; 20: 1897-902.

32 Mittwoch U, Mahadevaiah SK. Unpaired chromosomes at meiosis: cause or effect of gametogenic insufficiency? Cytogenet Cell Genet 1992; 59: 274-9.

33 Sun F, Turek P, Greene C, Ko E, Rademaker A et al. Abnormal progression through meiosis in men with nonobstructive azoospermia. Fertil Steril 2007; 87: 565-71.

34 Koren A, Ben-Aroya S, Kupiec M. Control of meiotic recombination initiation: a role for the environment? Curr Genet 2002; 42: 129-39.

35 Gonsalves J, Sun F, Schlegel PN, Turek PJ, Hopps CV et al. Defective recombination in infertile men. Hum Mol Genet 2004; 13: 2875-83.

36 Sun F, Greene C, Turek PJ, Ko E, Rademaker A et al. Immunofluorescent synaptonemal complex analysis in azoospermic men. Cytogenet Genome Res 2005, 111: 366-70.

37 Topping D, Brown P, Judis L, Schwartz S, Seftel A et al. Synaptic defects at meiosis I and non-obstructive azoospermia. Hum Reprod 2006; 21: 3171-7.

38 Barlow AL, Hulten MA. Crossing over analysis at pachytene in man. Eur J Hum Genet 1998; 6: 350-8.

39 Hassold T, Judis L, Chan ER, Schwartz S, Seftel A et al. Cytological studies of meiotic recombination in human males. Cytogenet Genome Res 2004; 107: 249-55.

40 Lynn A, Koehler KE, Judis L, Chan ER, Cherry JP et al. Covariation of synaptonemal complex length and mammalian meiotic exchange rates. Science 2002; 296 : 2222-5.

41 Sun F, Trpkov K, Rademaker A, Ko E, Martin RH. Variation in meiotic recombination frequencies among human males. Hum Genet 2005; 116: 172-8.

42 Sun F, Oliver-Bonet M, Liehr T, Starke H, Turek P et al. Analysis of non-crossover bivalents in pachytene cells from 10 normal men. Hum Reprod 2006; 21 : 2335-9.

43 Codina-Pascual M, Oliver-Bonet M, Navarro J, Campillo M, Garcia F et al. Synapsis and meiotic recombination analyses: MLH1 focus in the XY pair as an indicator. Hum Reprod 2005; 20: 2133-9.

44 Sun F, Oliver-Bonet M, Liehr T, Starke H, Turek P et al. Variation in MLH1 distribution in recombination maps for individual chromosomes from human males. Hum $\mathrm{MO}$ Genet 2006; 15: 2376-91.

45 Oliver-Bonet M, Liehr T, Nietzel A, Heller A, Starke $\mathrm{H}$ et al. Karyotyping of human synaptonemal complexes by cenM-FISH. Eur J Hum Genet 2003; 11: 879-83.

46 Ma S, Ferguson KA, Arsovska S, Moens P, Chow V. Reduced recombination associated with the production of aneuploid sperm in an infertile man: a case report. Hum Reprod 2006; 21: 980-5.

47 Hassold T, Hunt P. To err (meiotically) is human: the genesis of human aneuploidy. Nat Rev Genet 2001; 2: 280-91.

48 Hale DW. Is $X-Y$ recombination necessary for spermatocyte survival during mammalian spermatogenesis? Cytogenet Cell Genet 1994; 65: 278-82.

49 Christensen GL, Ivanov IP, Atkins JF, Mielnik A, Schlegel PN et al. Screening the SPO11 and EIF5A2 genes in a population of infertile men. Fertil Steril 2005; 84: 758-60.

50 Stouffs K, Lissens W, Tournaye H, van Steirteghem A, Liebaers I. SYCP3 mutations are uncommon in patients with azoospermia. Fertil Steril 2005; 84: 1019-20.

51 Westerveld GH, Repping S, Lombardi MP, van der Veen F. Mutations in the chromosome pairing gene FKBP6 are not a common cause of non-obstructive azoospermia. Mol Hum Reprod 2005; 11: 673-5.

52 Mori T, Kurahashi H, Shinka T, Nakahori Y, Taniguchi M et al. Candidate genes for male factor infertility-validation. Fertil Steril 2006; 86: 1553-4; author reply 4.

53 Miyamato T, Sato H, Yogev L, Kleiman S, Namiki M et al. Is a genetic defect in Fkbp6 a common cause of azoospermia in humans? Cell Mol Biol Lett 2006; 11: 557-69.

54 Zhang W, Zhang S, Xiao C, Yang Y, Zhoucun A. Mutation screening of the FKBP6 gene and its association study with spermatogenic impairment in idiopathic infertile men. Reproduction 2007; 133: 511-6.

55 Martinez J, Bonache S, Carvajal A, Bassas L, Larriba S. Mutations of SYCP3 are rare in infertile Spanish men with meiotic arrest. Fertil Steril 2007; 88: 988-9.

56 Zhang W, Yang Y, Su D, Ma Y, Zhang S. Absence of the H2AX mutations in idiopathic infertile men with spermatogenic impairment. Syst Biol Reprod Med 2008; 54: 93-5.

57 Griffin J, Emery BR, Christensen GL, Carrell DT. Analysis of the meiotic recombination gene $R E C 8$ for sequence variations in a population with severe male factor infertility. Syst Biol Reprod Med 2008; 54: 163-5.

58 Baudat F, de Massy B. SPO11: an activity that promotes DNA breaks required for meiosis. Med Sci (Paris) 2004; 20: 213-8. French.

59 Henderson KA, Keeney S. Tying synaptonemal complex initiation to the formation and programmed repair of DNA double-strand breaks. Proc Natl Acad Sci USA 2004; 101: 4519-24.

60 Botelho RJ, DiNicolo L, Tsao N, Karaiskakis A, Tarsounas M et al. The genomic structure of SYCP3, a meiosis-specific gene encoding a protein of the chromosome core. Biochim Biophys Acta 2001; 1518: 294-9.

61 Kolas NK, Yuan L, Hoog C, Heng HH, Marcon E et al. Male mouse meiotic chromosome cores deficient in structural proteins SYCP3 and SYCP2 align by homology but fail to synapse and have possible impaired specificity of chromatin loop attachment. Cytogenet Genome Res 2004; 105: 182-8.

62 Yuan L, Liu JG, Hoja MR, Wilbertz J, Nordqvist K et al. Female germ cell aneuploidy and embryo death in mice lacking the meiosis-specific protein SCP3. Science 2002; 296: 1115-8.

63 Tempest HG, Griffin DK. The relationship between male infertility and increased levels of sperm disomy. Cytogenet Genome Res 2004; 107: 83-94. 
64 Shi Q, Martin RH. Aneuploidy in human spermatozoa: FISH analysis in men with constitutional chromosomal abnormalities, and in infertile men. Reproduction $2001 ; 121$ : 655-66.

65 Finch KA, Fonseka KG, Abogrein A, Ioannou D, Handyside AH et al. Nuclear organization in human sperm: preliminary evidence for altered sex chromosome centromere position in infertile males. Hum Reprod 2008; 23: 1263-70.

66 Hassold T, Hunt PA, Sherman S. Trisomy in humans: incidence, origin and etiology. Curr Opin Genet Dev 1993; 3: 398-403.

67 Sun F, Mikhaail-Philips M, Oliver-Bonet M, Ko E, Rademaker A et al. The relationship between meiotic recombination in human spermatocytes and aneuploidy in sperm. Hum Reprod 2008; 23: 1691-7.

68 Bernardini L, Gianaroli L, Fortini D, Conte N, Magli C et al. Frequency of hyper-, hypohaploidy and diploidy in ejaculate, epididymal and testicular germ cells of infertile patients. Hum Reprod 2000; 15: 2165-72.

69 Palermo GD, Colombero LT, Hariprashad JJ, Schlegel PN, Rosenwaks Z. Chromosome analysis of epididymal and testicular sperm in azoospermic patients undergoing ICSI. Hum Reprod 2002; 17: 570-5.

70 Benzacken B, Gavelle FM, Martin-Pont B, Dupuy O, Lievre N et al. Familial sperm polyploidy induced by genetic spermatogenesis failure: case report. Hum Reprod 2001; 16: 2646-51.

71 Devillard F, Metzler-Guillemain C, Pelletier R, DeRobertis C, Bergues U et al. Polyploidy in large-headed sperm: FISH study of three cases. Hum Reprod 2002; 17: 1292-8.

72 In't Veld PA, Broekmans FJ, de France HF, Pearson PL, Pieters MH et al. Intracytoplasmic sperm injection (ICSI) and chromosomally abnormal spermatozoa. Hum Reprod 1997; 12: 752-4.

73 Lewis-Jones I, Aziz N, Seshadri S, Douglas A, Howard P. Sperm chromosomal abnormalities are linked to sperm morphologic deformities. Fertil Steril 2003; 79: 212-5.

74 van Steirteghem A, Bonduelle M, Devroey P, Liebaers I. Follow-up of children born after ICSI. Hum Reprod Update 2002; 8: 111-6.

75 Hassold TJ, Sherman SL, Pettay D, Page DC, Jacobs PA. XY chromosome nondisjunction in man is associated with diminished recombination in the pseudoautosomal region. Am J Hum Genet 1991; 49: 253-60.

76 Primig M, Williams RM, Winzeler EA, Tevzadze GG, Conway AR et al. The core meiotic transcriptome in budding yeasts. Nat Genet 2000; 26: 415-23.

77 Chu S, DeRisi J, Eisen M, Mulholland J, Botstein D et al. The transcriptional program of sporulation in budding yeast. Science 1998; 282: 699-705.
78 Aston KI, Krausz C, Laface I, Ruiz-Castane E, Carrell DT. Evaluation of 172 candidate polymorphisms for association with oligozoospermia or azoospermia in a large cohort of men of European descent. Hum Reprod 2010; 25: 1383-97.

79 Manolio TA, Collins FS, Cox NJ, Goldstein DB, Hindorff LA et al. Finding the missing heritability of complex diseases. Nature 2009; 461: 747-53.

80 Carrell DT, Wilcox AL, Lowy L, Peterson CM, Jones KP et al. Elevated sperm chromosome aneuploidy and apoptosis in patients with unexplained recurrent pregnancy loss. Obstet Gynecol 2003; 101: 1229-35.

81 Carrell DT. The clinical implementation of sperm chromosome aneuploidy testing: pitfalls and promises. J Androl 2008; 29: 124-33.

82 Tempest HG, Homa ST, Routledge EJ, Garner A, Zhai XP et al. Plants used in Chinese medicine for the treatment of male infertility possess antioxidant and anti-oestrogenic activity. Syst Biol Reprod Med 2008; 54: 185-95.

83 Martin R. The clinical relevance of sperm aneuploidy. In: Carell D, editor. The Genetics of Male Infertility. Totowa, , NJ: Humana Press Inc.; 2007. pp129-44.

84 Carrell DT, Hammoud SS. The human sperm epigenome and its potential role in embryonic development. Mol Hum Reprod 2010; 16: 37-47.

85 Jenkins TG, Carrell DT. The paternal epigenome and embryogenesis: poising mechanisms for development. Asian J Androl 2010; 13: 76-80.

86 Garcia-Herrero S, Garrido N, Martinez-Conejero JA, Remohi J, Pellicer A et al. Ontological evaluation of transcriptional differences between sperm of infertile males and fertile donors using microarray analysis. J Assist Reprod Genet 2010; 27: 111-20.

87 Sutovsky P, Neuber E, Schatten G. Ubiquitin-dependent sperm quality control mechanism recognizes spermatozoa with DNA defects as revealed by dual ubiquitin-TUNEL assay. Mol Reprod Dev 2002; 61: 406-13.

88 Ioannou D, Griffin DK. Male fertility, chromosome abnormalities, and nuclear organization. Cytogenet Genome Res; e-pub ahead of print 19 November 2010; doi: $10.1159 / 000322060$

89 Lalancette C, Platts AE, Johnson GD, Emery BR, Carrell DT et al. Identification of human sperm transcripts as candidate markers of male fertility. J Mol Med 2009; 87: 735-48.

90 Oliva R, Castillo J. Proteomics and the genetics of sperm chromatin condensation. Asian J Androl 2010; 13: 24-30.

91 Barratt CL, Aitken RJ, Bjorndahl L, Carrell DT, de Boer P et al. Sperm DNA: organization, protection and vulnerability: from basic science to clinical applications-a position report. Hum Reprod 2010; 25: 824-38.

92 Tempest HG, Homa ST, Zhai XP, Griffin DK. Significant reduction of sperm disomy in six men: effect of traditional Chinese medicine? Asian J Androl 2005; 7: 419-25. 